\title{
Information Support of Youth Policy as a Factor of Formation of the Social Capital and Political Attitudes of the Young Generation
}

\author{
Galina Viktorovna Morozova ${ }^{1}$, Artur Romanovich Gavrilov ${ }^{1} \&$ Bulat Ildarovich Yakupov $^{1}$ \\ ${ }^{1}$ Kazan Federal University, Russia \\ Correspondence: Galina Viktorovna Morozova, Kazan Federal University, Russia. E-mail: \\ galina.morozova@kpfu.ru
}

Received: June 9, 2019

Accepted: August 25, $2019 \quad$ Online Published: August 31, 2019

doi:10.5539/jpl.v12n5p88

URL: https://doi.org/10.5539/jpl.v12n5p88

\begin{abstract}
If we sum up the tasks facing the Russian state in relation to the young generation, then all of them are associated with its harmonious inclusion in the social and political development of the country. At the normative level, the current need is declared for young people to form active citizenship and democratic political culture, which is possible only in a constant and equal dialogue between the authorities and young people. Ensuring the interaction of the younger generation with the political elite presupposes the existence of certain conditions - the creation and effective functioning of the information infrastructure of youth policy, as well as the conduct of an open active information policy.

The article describes the results of a study of the political status of students of the capital of Tatarstan - Kazan, in particular, such parameters as youth interest in political information, trust in the sources of this information, and political participation. Together with the data of secondary studies, this made it possible to characterize the youth sector of political communication, identify the existing difficulties in the interaction of the government and youth, in particular, identify some difficulties in receiving and disseminating political information among the youth, which impede the development of a democratic political culture and the accumulation of social capital of the young generation.
\end{abstract}

Keywords: political culture, students, youth, information, communication

\section{Introduction}

The political socialization of youth today occurs under great uncertainty and fragmentation of information flows. It should be borne in mind that the value-normative system of youth is not always stable; youth not always knows the ropes of the socio-political situation, which can threaten information security in the state. Successful political socialization requires an equal dialogue between young people and state authorities. An important condition for including the younger generation in political life is an efficiently functioning media environment, an active state information policy related to the dissemination of information that meets the interests of the state and civil society, and aimed at ensuring their constructive dialogue and interaction.

The image of a young man created in normative acts in Russia suggests that in order to participate in youth policy, young people themselves should be interested and able to receive information from politicians and state authorities. In this regard, the condition for increasing the effectiveness of information support for youth policy should be the creation of a unified information network to support youth, its initiatives, and strengthen the feedback of youth with government agencies and public associations. It is significant that in European countries the issues of informing youth are considered as a key setting for understanding youth as a full-fledged actor in the implementation of youth policy. It is no coincidence that the European Charter, as well as other documents defining the main directions of development of the youth policy of national states, as an important component include the constant informing of youth communities, the provision of communication tools to involve young people in determining the priorities for social development of the younger generation.

Information support of the activities of the state and other socio-political institutions, as well as information policy, as a whole can affect the formation of the social capital of society, including youth. Social capital is an integral part of the political culture of civil society. It includes the norms and values of trust, reciprocity, and plays a significant role in the formation of civic identity. Thus, A. Tagfel's concept emphasizes the importance of positive acceptance 
of group affiliation and identification with the group, which motivates the group member to take an active life position and protect the interests of his group. In addition, a stable social identity is a condition for strengthening the individual's social ties, regulating his behavior and accepting social norms. Thus, the social identity of an individual can be considered as an essential component of social capital.

An equally significant component of social capital is civic and political involvement. Channels of civic engagement, like associations, political parties, represent horizontal ties. An expression of the presence of social capital, institutional trust (mistrust) can be participation in mass politics in various forms. Thus, studies show that politically active people have a higher level of social trust. "Self-authorized" people, twice the number of "alienated", participated in the work of charitable foundations or made donations thereto. They are more interested in politics and better versed in it, more actively use the Internet, newspapers, friends, and colleagues as a source of information.

According to Putnam, government bodies, along with public organizations, parties, and movements, educational organizations, business communities belong to centers who build social capital in society. A. Vissarionov believes that at the present stage, state regulation of the development of social capital in Russia is advisable, stimulating the formation of social, interpersonal relationships, ties in the business community, industry. This can be expressed, in particular, in stimulating the development of communications, telecommunications, in creating partnerships with non-governmental organizations supported by civil society, etc. - all that today relates to the tasks of the state's information policy.

Speaking of information policy as a factor in the formation of institutional trust and mistrust, it is worth mentioning the theoretical model by P. Stomka as well. He formulates five reasons contributing to the emergence of a culture of trust, among which are transparency of social organization as opposed to secrecy, a sense of comprehension of the surrounding world as opposed to a feeling of the unknown, accountability of other people and institutions as opposed to arbitrariness and irresponsibility. As we can see, these factors require an open and transparent information policy of public authorities and public institutions.

\section{Methods}

The empirical basis of the study was the data of the Federal State Statistics Service, the results of the study "Youth Attitudes to Politics, Elections, and Sources of Political Information" conducted by the Central Election Commission of the Republic of Tatarstan and Kazan Federal University on October 10 to October 24, 2018, as well as data of the studies of features of social well-being of student youth. As a method of collecting primary sociological information, a mass questionnaire was selected. During the study, a non-continuous quota sample was used. The total population was 40,000 students as of 19.12.2017.

The calculation of the sample was carried out according to the formula:

$\mathbf{S S}=\mathbf{Z}^{2 *}(\mathbf{p}) *(1-\mathbf{p}) / \mathbf{C}^{2}$

where:

$\mathbf{Z}=\mathrm{Z}$-factor (95\% confidence interval)

$\mathbf{p}=$ percentage of respondents or answers interested, in decimal form $(0.5$ by default $)$

$\mathbf{c}=$ confidence interval, in decimal form (e.g. $0.05= \pm 5 \%$ ).

Thus, the total sample was 382 respondents (with a sampling error of 5\%), taking into account the territorial-settlement character, areas of study (humanists and engineers) and socio-demographic characteristics with the following age groups: 18-19 years old, 20-24 years old.

Statistical processing was carried out using Microsoft Office Excel application packages. The experimental base of the research was the respondents of Kazan Federal University. The majority of the respondents were 2nd and 4th-year students, of which $27 \%$ were young men, and $73 \%$ - girls.

\section{Results}

According to the survey, less than half of the respondents (40.1\%) are interested in politics. Moreover, in the hierarchy of preferred types of information, political information is an absolute outsider (3.2\%), inferior to all other types (leader - entertaining, second place - cognitive information). It is noteworthy that when answering the question "How often do you read the news on political topics?" $33 \%$ of respondents answered negatively, and $44.3 \%$ of respondents related their interest only to major political events. Less than $10 \%$ regularly participate in the discussion of news on political topics, and about a third of respondents (32\%) indicated that they do this occasionally. The results can be considered as evidence of a certain indifference of students to information of a 
political nature. Young people are not interested in Russian politicians, their opinions, and assessments. When answering the question "Do you read blogs/posts of politicians?" half of the respondents $(50.5 \%)$ answered negatively; $39.4 \%$ of respondents said that they sometimes look at such information, and only $7.6 \%$ discuss these topics with friends. According to the data obtained, in the hierarchy of vital interests of student youth, politics occupies only fifth place (13.8\%), giving way to family (81.3\%), work (65.5\%), education (64.3\%), leisure (59.1\%) and being ahead of only religion (5.7\%), which allows us to conclude that the respondents' interest in political information is situational in nature and is associated mainly with major socio-political events.

At the same time, to the question of "What problem in the life of Russia does excite you the most?", which controls the survey data related to determining the level of youth's interest in political information, only $4 \%$ of respondents said that they were not worried, and 3\% - found it difficult to answer. The vast majority of those participating in the 2018 study is good at the ongoing processes and adequately assess the current problems. One of two (53\%) is concerned about corruption in government structures, more than a third of respondents (37.3\%) noted "inflation, rising prices" as their most significant problem. The third place in the rank of problems that concern youth the most belongs to the state of healthcare and education, which was emphasized by $33.4 \%$.

The presence of interest in political events is also evidenced by the data obtained in the study of the electoral activity of students during electoral cycles, in particular, participation in voting. To the question of "Did you participate in the elections in September 2015 in Russia?" almost every second respondent (46.1\%) answered "yes", and 49\% took part in the 2018 elections.

At the same time, the obtained data revealed significant flaws in the information support of the election procedure. Thus, the surveyed young people have experienced a certain lack of information about candidates (28.6\%) and parties (24.4\%) participating in the elections. At the same time, according to the results obtained, they know and understand the procedural aspects: $39.4 \%$ of respondents have an idea about the activities of election commissions, and also believe that they know their voting rights. The vast majority (68.7\%) of young people are aware of where their polling site. $33 \%$ of respondents do not experience "information hunger" during the election and believe that the information provided is sufficient.

Perhaps, for this reason, that is, due to a lack of information, the majority of the youth surveyed (45.30\%) advocate the creation of special information resources clearly explaining the situation with elections.

Regarding the most preferred sources of political (as well as any other) information among youth, one can confidently talk about the priority of Internet information. $90.4 \%$ of respondents prefer to search for relevant information on the Internet, in second place $(27.3 \%)$ - television, the press - 5.4\%, radio - 3.9\%. Among social networks, VKontakte and Instagram are the most popular $-88.4 \%$ and $80.8 \%$, respectively. The most popular instant messengers for young people are Whatsapp (82.5\%), Telegram (52.2\%), and VKontakte messenger application (34.5\%). $72.2 \%$ of those polled specifically name the Internet (including social networks) the main source of political information. The work on building communication on the Internet, therefore, is the most promising in terms of attracting the attention of this demographic group. However, it should be noted that more than half of the total number of respondents (51.5\%) found it difficult to answer the question "Do you trust information from official sources (websites of political parties, authorities, blogs of Russian politicians, etc.) on the Internet?" Only $23.6 \%$ answered yes and $24.9 \%$ did not trust them. Obviously, young people are quite negative about any form of direct political advertising and propaganda. The main motives of young people in the process of communication, including political, are the free exchange of information and the possibility of independent production.

\section{Summary}

Political communications researcher Stephen Coleman speaks about the possibility of the implementation of six communicative functions by citizens of a democratic society. He names dissemination of experience, collection of information, democratic discussion, collective action, consultation and participation of citizens, as well as control. Given that the youth of Russia, as shown by the results above, prefers the Internet as the main source of information, we consider it appropriate to continue the discussion in this vein. We have considered the possibility of implementing functions that are closely related to the implementation of information support for youth policy in Russia, as an important condition for successful political socialization of young people and building up their social capital. The analysis of the information resources of the youth of Russia showed that their content covers the audience of all regions of Russia, reflects global news, but the presence of local news is limited to regional digests in the field of youth policy. Information resources do not always provide complete, comprehensive information about events, meetings, forums. Feedback does not always have a response, as evidenced by the fact that social networks contain negative comments from young people left unanswered. The content of the site is often 
overloaded with news from various events, which make it difficult to find information on the activities of a department and its subordinate institutions for the implementation of youth policy. Analysis of the work in the information space of many regional departments for youth affairs allows us to assess its quality as unsatisfactory, neglecting the characteristics of the target audience. At the regional level, the information content of state bodies implementing youth policy is characterized, as a rule, by the "dry" official language of materials, untimely publication of the reporting form, poor knowledge of modern media technologies, incompleteness and inaccuracy of published data. All this not only violates the principle of information transparency of the authorities but also reduces the level of youth's confidence in official sources of information, forcing it to get information through other channels.

\section{Conclusion}

Information policy of the state, as well as information support of youth policy, has a strong influence on the formation of social capital and the nature of the political culture of the young generation. This is especially true for Russia, where the information society develops actively, new forms of e-democracy appear, and youth is the group that is at the forefront of mastering digitalization trends. The evidence is the results of a study demonstrating that the Internet is now becoming the main source of information, including political information, for young people. The analyzed process of mastering the norms of social trust, the opportunities provided to the young generation by society and the state for the implementation of the main communicative functions in the online environment, allow us to establish the formation of a positive social capital for young people. At the same time, a number of problems have been identified whose solution should make up the agenda of modern information policy in Russia. The key task of the state and the public should be the development of a detailed concept of working with young people, including a section on information policy. Today, the government of the country uses far from all the possibilities of the Internet, strictly doses information, which cannot but affect the level of trust in authorities, and there's no need to talk about forms of full participation of youth in the development and decision-making. In contrast to democratic societies where the state that promotes interests of its citizens supports the increase of social capital, Russia shows a reverse trend - it restricts public communications that may cause for the authorities the loss of their positions, increase social capital, and the government will follow the path of greater control over the political discourse to increase the social capital.

\section{Acknowledgemnts}

The work is performed according to the Russian Government Program of Kazan Federal University.

\section{References}

Coleman, S. (2017). Can The Internet Strengthen Democracy. John Wiley \& Sons AND Sons LTD.

Dice, M. (2017). The True Story of Fake News: How Mainstream Media Manipulates Millions. The Resistance Manifesto.

Eidelson, R. (2018). Political Mind Games. How the 1\% Manipulate Our Understanding of What's Happening, What's Right, and What's Possible. Green Hall Books.

Florela, V. C. (2016). Political Attitudes. Computational and Simulation Modelling. John Wiley \& Sons Limited (prof) EUR.

Grasso, M. T. (2016). Generations, Political Participation and Social Change in Western Europe. Routledge.

Grigorievna, A. S., \& Mikhailovna, B. I. (2016). Mass politics: institutional foundations. Political Encyclopedia.

Kibanov, A. Ia., Lovcheva, M. V., \& Lukianova, T. V. (2016). The implementation of youth policy in the Russian Federation. Infra-M.

Pereverzev, M. P., \& Kalinina, Z. N. (2019). Management in youth policy. Textbook, INFRA-M.

Rostovskaia, T. K., \& Petrova, T. E. (2018). International experience in the implementation of state youth policy. Textbook. INFRA-M. https://doi.org/10.12737/textbook_5a2f878ec0a3d8.31968217

Shtompka, P. (2016). Trust is the basis of society. Logos.

\section{Copyrights}

Copyright for this article is retained by the author(s), with first publication rights granted to the journal.

This is an open-access article distributed under the terms and conditions of the Creative Commons Attribution license (http://creativecommons.org/licenses/by/4.0/). 